\title{
Spatial distribution and focal mechanisms of aftershocks of the 2011 off the Pacific coast of Tohoku Earthquake
}

\author{
Youichi Asano ${ }^{1}$, Tatsuhiko Saito ${ }^{1}$, Yoshihiro Ito $^{2}$, Katsuhiko Shiomi $^{1}$, Hitoshi Hirose ${ }^{1}$, \\ Takumi Matsumoto ${ }^{1}$, Shin Aoi ${ }^{1}$, Sadaki Hori ${ }^{1}$, and Shoji Sekiguchi ${ }^{1}$ \\ ${ }^{1}$ National Research Institute for Earth Science and Disaster Prevention, 3-1 Tennodai, Tsukuba 305-0006, Japan \\ ${ }^{2}$ Research Center for Prediction of Earthquakes and Volcanic Eruptions, Graduate School of Science, \\ Tohoku University, 6-6 Aza-Aoba, Aramaki, Aoba-ku, Sendai 980-8578, Japan
}

(Received April 15, 2011; Revised June 9, 2011; Accepted June 10, 2011; Online published September 27, 2011)

\begin{abstract}
We estimated centroid moment tensors of earthquakes that occurred from 2003 to 2011 in and around the focal area of the $2011 M_{\mathrm{w}} 9.0$ megathrust earthquake in eastern Japan. The result indicates that earthquakes occurring before the mainshock, which included foreshocks off Miyagi, were basically interplate earthquakes with thrusttype focal mechanisms. On the other hand, the aftershocks exhibited a variety of focal mechanisms. Interplate aftershocks with thrust focal mechanisms did not occur within the large coseismic slip area estimated from GPS data but instead occurred in the surrounding regions. This implies that slip could no longer occur in the coseismic slip area due to the large amount of stress release during the mainshock rupture, whereas the aftershocks in the surrounding regions were caused by a stress concentration in these regions due to the large co-seismic slip associated with the mainshock asperity. Normal-fault-type aftershocks were widely distributed in the overriding plate and the outer-rise of the Pacific Plate. These aftershocks may have been due to a tensional stress change caused by the coseismic slip. Thrust-fault-type aftershocks in the subducting Pacific Plate were also interpreted as being due to compressional stress change as a result of the coseismic slip.
\end{abstract}

Key words: Foreshock, aftershock, centroid moment tensor, focal mechanism.

\section{Introduction}

The 2011 off the Pacific coast of Tohoku Earthquake with a moment magnitude $\left(M_{\mathrm{w}}\right)$ of 9.0 (e.g., Japan Meteorological Agency, 2011; United States Geological Survey, 2011) occurred at 5:46 (UTC) on March 11, 2011 along the boundary between the subducting Pacific Plate and the overriding plate. Preceding this $M_{\mathrm{w}} 9.0$ earthquake, an $M_{\text {JMA }} 7.3$ earthquake occurred on March 9. This earthquake and its aftershocks can be regarded as foreshocks to the $M_{\mathrm{w}} 9.0$ event. Since large earthquakes are likely to produce stress concentrations in neighboring regions along the plate boundary, the mainshock might have been triggered by this sequence of foreshocks and this mainshock have caused aftershocks. It is thus very important to determine the detailed locations and focal mechanisms of the foreshocks, mainshock, and aftershocks, in order to understand the physical relationship among them.

Ito et al. (2004) investigated the focal mechanisms of aftershocks of the 2003 Tokachi-oki earthquake $\left(M_{\mathrm{JMA}} 8.0\right)$ using moment tensor inversion. They revealed that aftershocks with similar focal mechanisms to that of the mainshock were distributed to the northeast of the mainshock and this aftershock area did not overlap with the coseismic slip area of the mainshock. In addition, aftershocks with

Copyright (c) The Society of Geomagnetism and Earth, Planetary and Space Sciences (SGEPSS); The Seismological Society of Japan; The Volcanological Society of Japan; The Geodetic Society of Japan; The Japanese Society for Planetary Sciences; TERRAPUB.

doi:10.5047/eps.2011.06.016 different types of focal mechanisms were distributed above and below the plate boundary. In their study, the horizontal locations of the centroids were set to those of the hypocenters determined by arrival time data. Ito et al. (2006), on the other hand, successfully estimated centroid moment tensor solutions providing centroid locations in addition to mechanism parameters using newly developed grid search and inversion techniques. They applied their method to data for inland earthquakes observed at stations distributed in onesided regions to simulate the station coverage of off-shore earthquakes, and compared the obtained centroid locations with the hypocenters precisely determined by dense observations. The estimated horizontal and vertical locations of the centroid moment tensors (CMTs) were respectively located within 10 and $15 \mathrm{~km}$ from the hypocenters. Their result showed that CMTs can be stably estimated even for off-shore earthquakes, for which hypocenter estimation is difficult using only $P$ - and $S$-wave arrival times due to poor coverage above the source area. Thus, such a CMT analysis can be a powerful tool for locating off-shore earthquakes and estimating their focal mechanisms. In the present paper, we apply this method to estimate the CMTs of earthquakes in and around the focal area of the $M_{\mathrm{w}} 9.0$ earthquake and we discuss their spatial distribution.

\section{Data and Analysis}

Seismograms observed at the F-net and Hi-net stations (Okada et al., 2004) (Fig. 1) operated by the National Research Institute for Earth Science and Disaster Prevention 
Table 1. Parameters for the CMT inversion.

\begin{tabular}{cccc}
\hline Classification by amplitude magnitude & $3.5 \leq M<5$ & $5 \leq M<6$ & $6 \leq M$ excepting 12 events \\
\hline Epicentral distance for station selection $(\mathrm{km})$ & $10-300$ & $100-400$ & $100-500$ \\
Waveform lengths for the CMT inversion (s) & 120 & 150 & 180 \\
Pass-band of the filter (Hz) & $0.02-0.05$ & $0.02-0.05$ & $0.02-0.05$ \\
Initial centroid time from origin time (s) & 0 & 0 & 500 \\
\hline
\end{tabular}

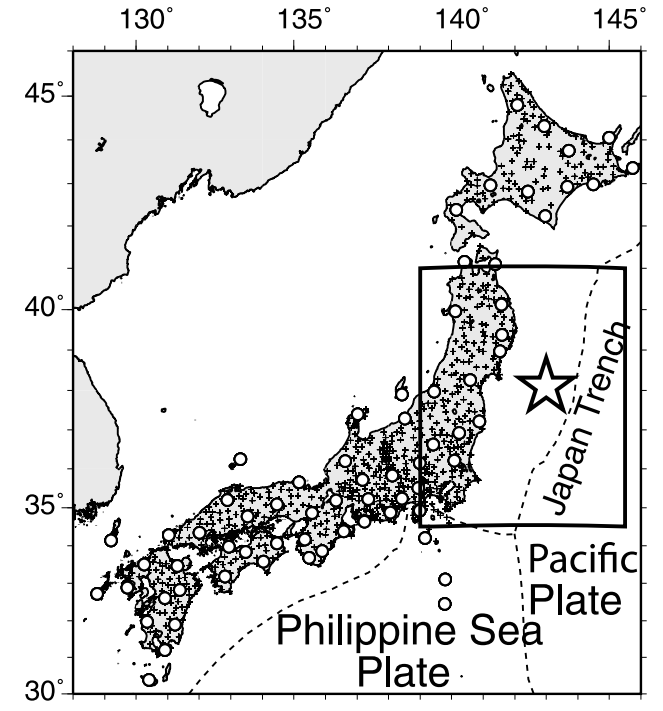

Fig. 1. Study area. The rectangular region indicates the focal area and its surroundings, as shown in Figs. 2 and 3. The mainshock epicenter is indicated by a star. Hi-net and F-net stations are shown by crosses and circles, respectively. Trenches and Troughs are indicated by dashed lines.

(NIED) were used to estimate CMTs by the inversion technique (Ito et al., 2006). In this inversion, five independent components of the moment tensor are estimated under an a priori traceless constraint assuming a centroid location, which is revised by a step-by-step procedure in their grid search algorithm.

Preprocessing of the data from broadband seismometers and high sensitivity accelerometers was carried out using basically the same procedure as Ito et al. (2006). Epicentral distance ranges for station selection, waveform lengths for the CMT inversion, pass-bands of the filters to be applied, and time shifts of initial centroids from the origin times were determined based on the amplitude magnitudes of the analyzed earthquakes obtained from normal hypocenter determination (Table 1). After preliminary station selection, we chose a maximum of $6 \mathrm{~F}$-net and $36 \mathrm{Hi}$-net stations for estimation of the final solution by considering the station coverage and the data quality for each station. The theoretical Green's function used in this study was also the same as used by Ito et al. (2006). Approximately 5,000 earthquakes with amplitude magnitudes $M \geq 3.5$ in the Hi-net catalogue from June 1, 2003 to May 24, 2011 (excluding some periods during 2005, 2006, and 2007) were analyzed in the present study.

\section{General Features of the Obtained CMTs}

We obtained CMTs for 1,970 earthquakes with variance reductions of $\geq 70 \%$ using at least 20 stations. Large earth- quakes, their later phases, and frequent aftershock occurrences often contaminate seismic signal from target earthquakes to estimate CMTs. Unfeasible locations and times of initial centroids also give rise to difficulties in CMT estimation. In the present study, we set the initial centroid locations to be the hypocenter locations from the Hi-net catalogue, which includes automatically determined hypocenters, especially for aftershocks. Some of these are likely to be inaccurate, which would prevent stable estimation during the CMT inversion process.

We could stably estimate the CMTs of 942 earthquakes that occurred before the $M_{\mathrm{w}} 9.0$ mainshock. Most of these were interplate earthquakes with thrust-type focal mechanisms (Figs. 2(a) and (c)). The $M_{\mathrm{w}} 7.3$ earthquake that occurred on March 9, 2011, and its 38 aftershocks, which can be considered to be the foreshocks of the $M_{\mathrm{w}} 9.0$ event, also had mainly thrust-type focal mechanisms and were distributed along the plate boundary in an approximately $90 \times 70 \mathrm{~km}^{2}$ region off Miyagi (Fig. 2(a)). The centroid of the largest foreshock $\left(M_{\mathrm{w}} 7.3\right)$ is located on the western edge of this region. The hypocenter of the $M_{\mathrm{w}} 9.0$ mainshock by the Hi-net preliminary catalogue was located at the southwestern edge of the area of foreshock activity, which yields stress concentration to the mainshock hypocenter and may trigger the initiation of the mainshock rupture (Fig. 2(a)).

On the other hand, for the 1,028 aftershocks that occurred in a wide area off Iwate, Miyagi, Fukushima, Ibaraki, and Chiba (Fig. 2(b)), the CMTs indicated that they were of mixed types. For example, the $M_{\mathrm{w}} 7.4$ and 7.6 earthquakes at 6:08 and 6:15, respectively, on March 11 were similar thrust-type earthquakes along the plate boundary to the $M_{\mathrm{w}} 9.0$ mainshock. However, an $M_{\mathrm{w}} 7.6$ normal-fault-type earthquake occurred in the outer-rise of the Pacific plate at 6:26 on March 9, an $M_{\mathrm{w}} 7.1$ thrust-type earthquake with a larger dip angle occurred in the subducting slab at 14:32 on April 7, and an $M_{\mathrm{w}} 6.7$ normal-fault-type earthquake occurred in eastern Fukushima at 8:16 on April 11 (Figs. 2(b) and $(d))$.

\section{Detailed Distribution of Interplate and Other Aftershocks}

In order to determine the detailed spatial distribution of the different types of aftershocks, we evaluated Kagan's angles (Kagan, 1991), which are the minimum rotation angles of the focal mechanisms relative to a reference mechanism corresponding to a typical interplate earthquake (strike $\phi=195^{\circ}, \operatorname{dip} \delta=13^{\circ}$, rake $\lambda=90^{\circ}$ ) in this region (Figs. 2(e) and (f)). The results indicate that the Kagan's angles of earthquakes occurring before the mainshock are mainly within 30 to $40^{\circ}$, especially for the earthquakes 
(a)

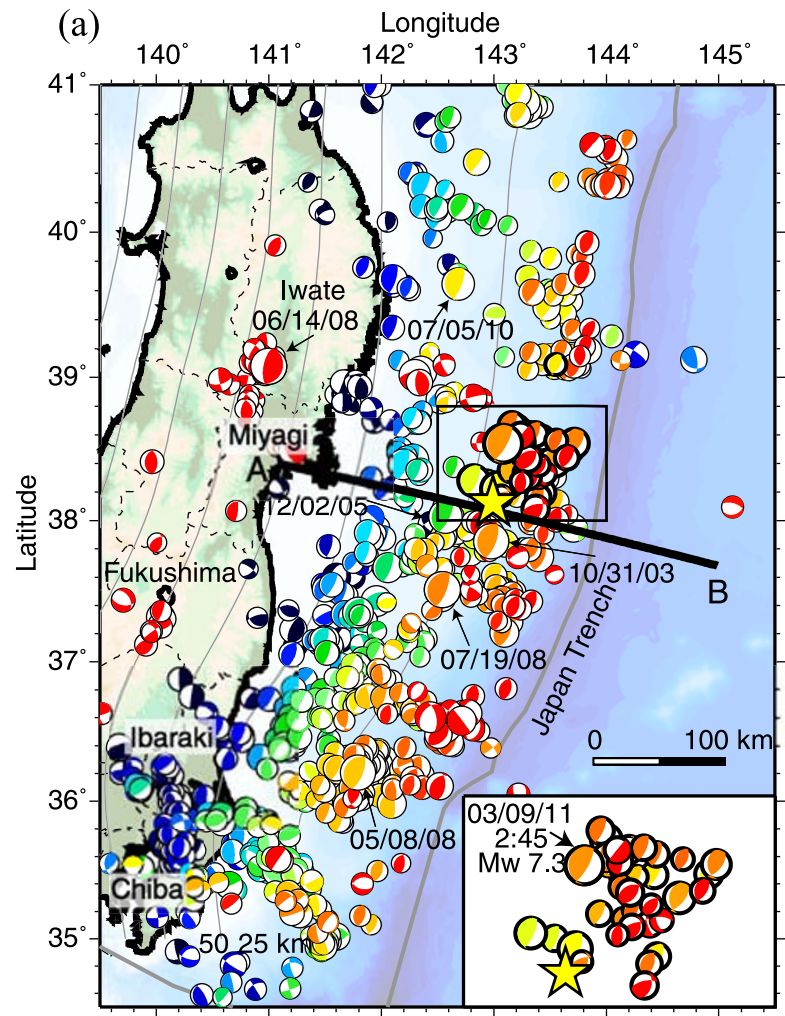

(c)

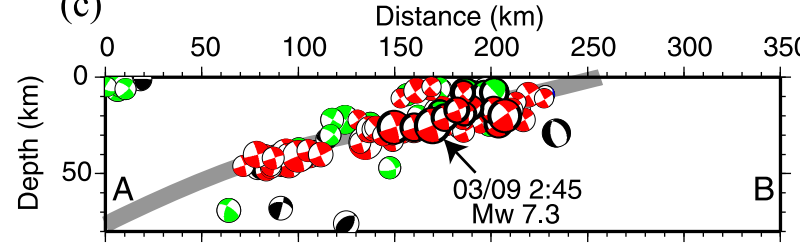

(e)

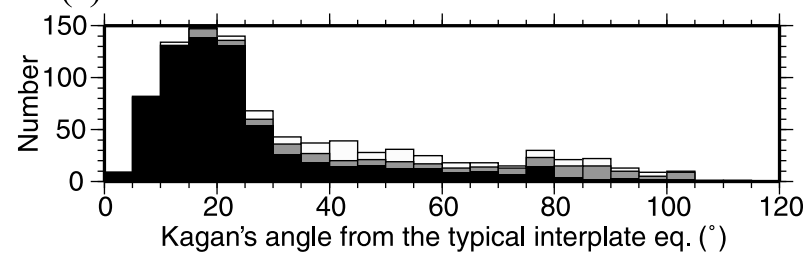

(b)

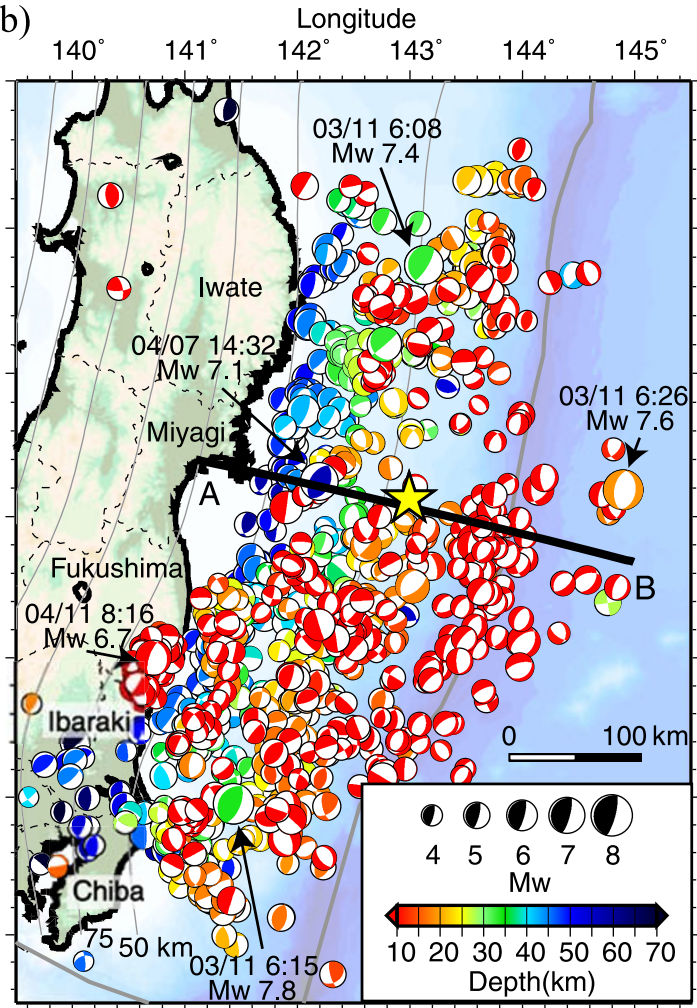

(d)

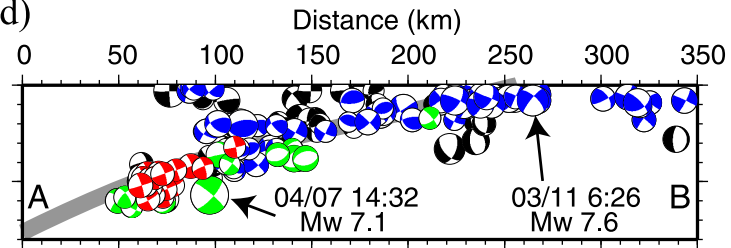

(f)

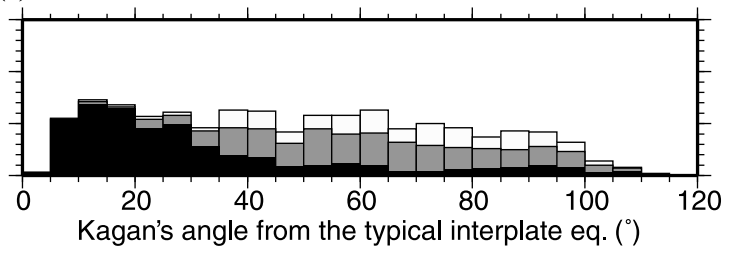

Fig. 2. Distribution of CMTs and Kagan's angles of earthquakes in periods (a) (c) (e) January 1, 2003-March 11 5:45, 2011 (before the mainshock) and (b) (d) (f) March 11 5:46-May 24, 2011 (after the mainshock). (a) and (b) show horizontal distributions; (c) and (d) show depth distributions along the thick black line AB. The size of the focal mechanism indicates the moment magnitude. The color scale denotes the centroid depth. Larger earthquakes plotted with their dates and times correspond to the 12 large events listed in Table 1. In (a) and (b), the inset shows the distribution of the CMTs of the foreshocks (focal mechanisms with thick outlines) that occurred in the two days prior to the mainshock in the rectangular area. The star indicates the mainshock epicenter. The gray thick and thin lines respectively denote the trench axis and depth contour of the subducting Pacific Plate (Hasegawa et al., 1994). In (c) and (d), red, green, blue, and black focal mechanisms respectively denote interplate type, thrust type, normal-fault type, and others. Thrust and normal-fault type earthquakes were selected from non-interplate earthquakes based on Frohlich (1992). In (e) and (f), the histograms show the angular distributions of Kagan's angles for the earthquakes. White, gray, and black respectively denote the histograms for all earthquakes, earthquakes that occurred within $20 \mathrm{~km}$ from the plate boundary, and earthquakes with rake $\lambda \geq 0$.

that occurred within $20 \mathrm{~km}$ from the plate boundary inferred from the depth distribution of the upper seismic plane along the subducting Pacific Plate (Hasegawa et al., 1994). On the other hand, the Kagan's angles of the aftershocks are broadly distributed even for selected earthquakes within $20 \mathrm{~km}$ from the plate boundary, which also include normalfault-type aftershocks near the trench and in the outer-rise. It is difficult to omit such normal-fault aftershocks and identify interplate aftershocks using only the Kagan's angle and depth information. Therefore, we defined such interplate aftershocks by the following conditions: rake $\lambda \geq 0^{\circ}$,
Kagan's angle $\theta \leq 35^{\circ}$, and centroid depth difference from the plate boundary $\delta d \leq 20 \mathrm{~km}$. Based on their CMTs, 315 aftershocks were regarded as interplate earthquakes (Fig. 3(a)); deeper interplate earthquakes (centroid depth $\geq$ $40 \mathrm{~km}$ ) were distributed off Iwate, Miyagi, Fukushima, and Ibaraki near the Pacific coast. On the other hand, shallower interplate earthquakes (centroid depth $<40 \mathrm{~km}$ ) occurred only off northern Iwate, Ibaraki, and Chiba. Note that no interplate earthquakes occurred in the region directly around the mainshock hypocenter.

The Geospatial Information Authority of Japan (2011) 


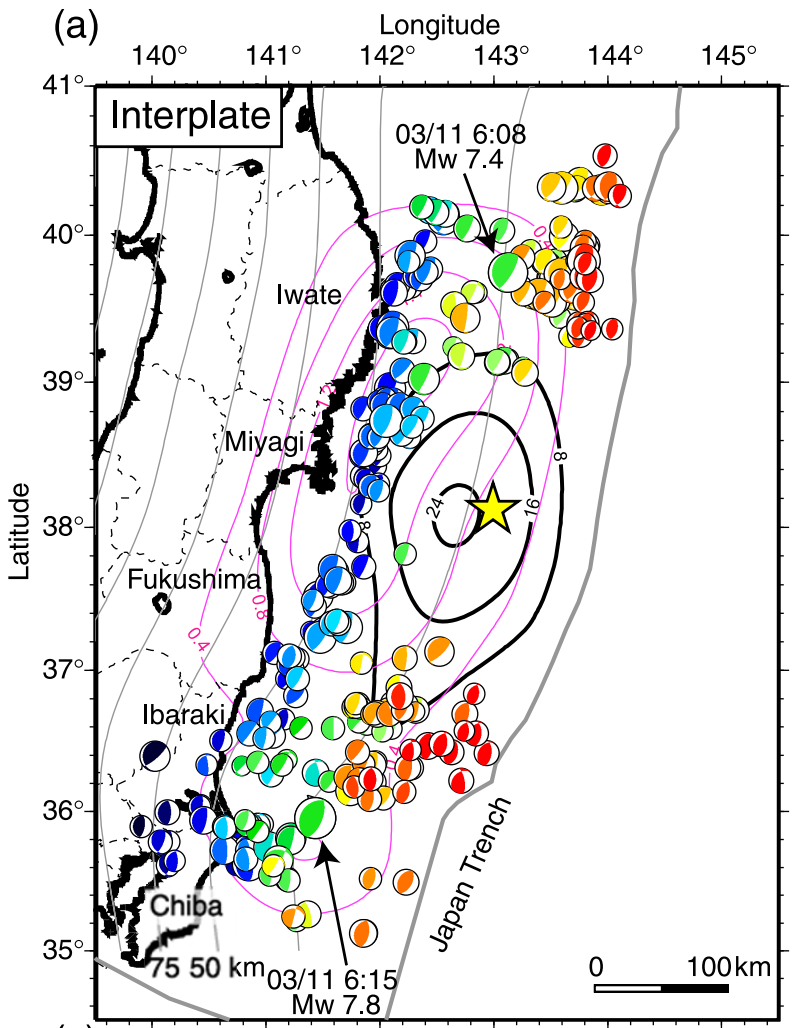

(C)

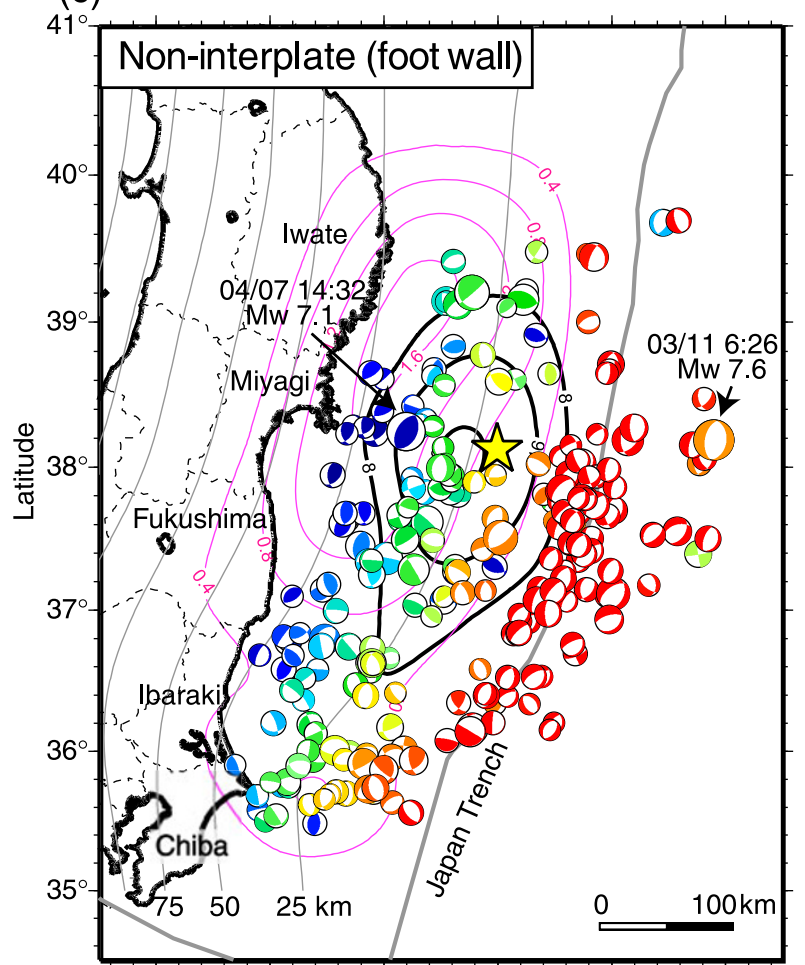

(b)
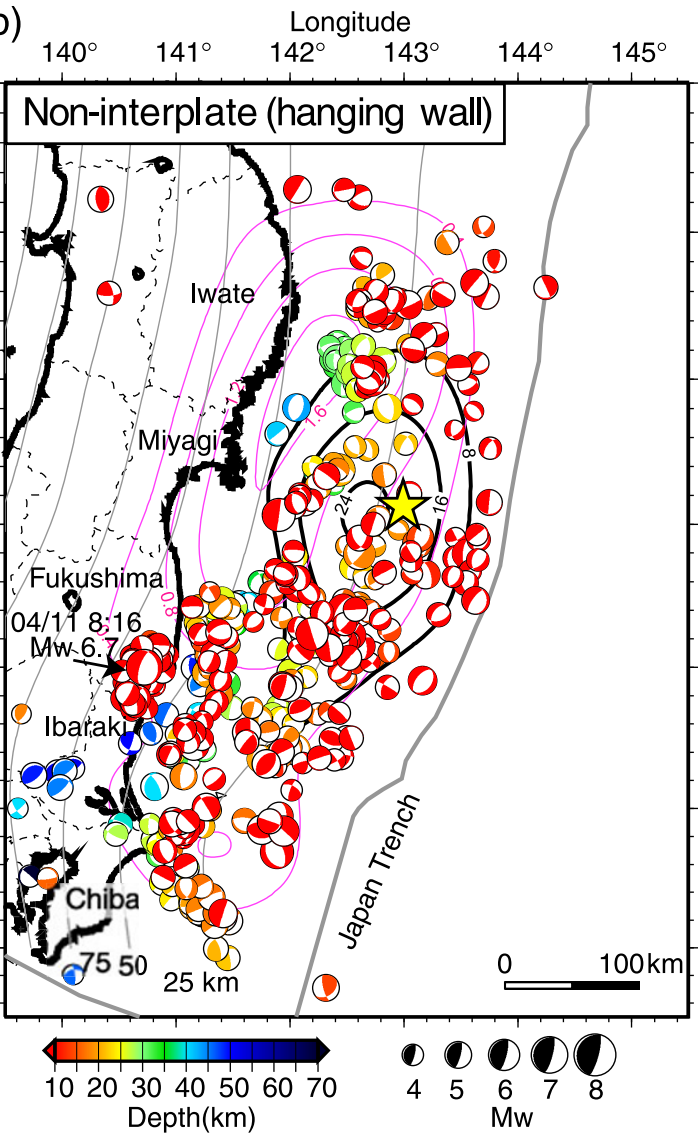

Fig. 3. Spatial distribution of CMTs of (a) interplate aftershocks, (b) non-interplate aftershocks in the hanging wall, and (c) non-interplate aftershocks in the foot wall. Symbols are the same as in Figs. 2(a) and (b). The black and pink contours respectively denote coseismic and postseismic slip estimated from GPS data observed in a period from March 11 9:00 to May 11 18:00, 2011 (Geospatial Information Authority of Japan, 2011). The contour intervals for coseismic and postseismic slip were 8.0 and $0.4 \mathrm{~m}$, respectively.

has estimated the spatial distribution of coseismic and postseismic slip from GPS data. They showed that the large coseismic slip ( $>8 \mathrm{~m}$ ) area extended from off southern Iwate to off Fukushima and that its largest peak ( $>24 \mathrm{~m})$ was located off Miyagi. The epicenter distribution of the 315 interplate aftershocks does not overlap with this large coseismic slip area (Fig. 3 (a)). This suggests that the large coseismic slip area, which is thought to correspond to the mainshock asperity, can no longer slip in the form of aftershocks due to the large amount of the stress release dur- 
ing the mainshock rupture. On the other hand, interplate aftershocks occurred in the northern, southern, and deeper extensions of the large coseismic slip area. These surrounding areas, which probably did not have large amount of coseismic slips, were primarily loaded by the coseismic slip of the mainshock asperity. In addition, a large amount of postseismic slip was estimated in the deeper extension of the large coseismic slip area off southern Iwate and Miyagi (Fig. 3(a)), which would also promote the occurrence of aftershocks along the plate boundary. Consequently, many interplate aftershocks may have occurred in this region.

Of the 1,028 aftershocks, 713 were identified as being non-interplate types. Instead, a variety of different focal mechanisms were found. In order to discuss the relationship between the coseismic stress change and the spatial distribution of these focal mechanisms, we plot the distribution of these non-interplate aftershocks in the hanging and foot walls in Fig. 3(b) and 3(c), respectively. In the hanging wall, normal faulting is predominant, although the $T$-axis directions of these aftershocks are scattered. In the foot wall, normal faulting with a $T$ axis along the east-west direction is predominant and these aftershocks are distributed along the Japan Trench near the large coseismic slip area (Fig. 3(c)). These normal-fault aftershocks near the trench and in the outer-rise occurred mainly in the up-dip portion (eastern part) of the foot wall of the large coseismic slip area; seismicity in this area may have been activated by a tensional stress change caused by the thrust faulting of the mainshock. The down-dip portion (western part) of the hanging wall was also subjected to a tensional stress change as a result of the mainshock. Therefore, some of the normalfault-type aftershocks in these regions, such as the shallow ( $\sim 10 \mathrm{~km})$ aftershocks near the Pacific coast of Fukushima, Ibaraki, and Chiba in Fig. 3(b), might have been activated by such a stress change. The western part of the foot wall is expected to have been subjected to a compressional stress change. Thrust aftershocks in this area that occurred within the subducting Pacific Plate (e.g. $M_{\mathrm{w}} 7.1$ at 14:32 on April 7, off Miyagi in Fig. 3(c)) may also have been activated by this compressional stress change.

\section{Conclusions}

We estimated the CMTs of earthquakes that occurred before and after the $2011 M_{\mathrm{w}} 9.0$ earthquake in eastern Japan. Most of the earthquakes before the mainshock had thrusttype focal mechanisms and occurred along the plate boundary. Foreshocks in the two days preceding the mainshock occurred in a localized area off Miyagi, and the $M_{\mathrm{w}} 9.0$ mainshock occurred at the southwestern edge of this foreshock area. On the other hand, the aftershocks exhibited various types of focal mechanisms. No interplate aftershocks occurred in the large coseismic slip area, but rather in the surrounding regions along the plate boundary, probably as a result of a stress concentration due to this large coseismic slip. Other aftershocks occurred in the Pacific Plate and the overriding plate, some of which are thought to have been caused by tensional and compressional stress changes, respectively, as a result of the mainshock.

Acknowledgments. In the present study, we used topographic data for inland and ocean areas respectively provided by the Geospatial Information Authority of Japan and the Japan Oceanographic Data Center. We thank L. Rivera and an anonymous reviewer for providing thoughtful reviews, which helped us to improve this manuscript. All figures were drawn using the software GMT (Wessel and Smith, 1995).

\section{References}

Frohlich, C., Triangle diagrams: ternary graphs to display similarity and diversity of earthquake focal mechanisms, Phys. Earth Planet. Inter., 75, 193-198, 1992.

Geospatial Information Authority of Japan, The 2011 off the Pacific coast of Tohoku Earthquake, Coseismic and postseismic slip distribution on the plate interface (preliminary result), http://www.gsi.go.jp/cais/topic110315.2-index-e.html, 2011.

Hasegawa, A., S. Horiuchi, and N. Umino, Seismic structure of the northeastern Japan convergent margin: A synthesis, J. Geophys. Res., 99, 22,295-22,311, 1994.

Ito, Y., H. Matsubayashi, H. Kimura, T. Matsumoto, Y. Asano, and S. Sekiguchi, Spatial distribution for moment tensor solutions of the 2003 Tokachi-oki earthquake $\left(M_{J M A}=8.0\right)$ and aftershocks, Earth Planets Space, 56, 301-306, 2004.

Ito, Y., S. Sekiguchi, T. Okada, R. Honda, K. Obara, and S. Hori, Performance of regional distance centroid moment tensor inversion applied to the 2004 mid-Niigata prefecture earthquake, Japan, Geophys. J. Int., 167, 1317-1331, 2006.

Japan Meteorological Agency, Report for The 2011 off the Pacific coast of Tohoku Earthquake (No. 15), http://www.jma.go.jp/ jma/press/1103/13b/kaisetsu201103131255.pdf, 2011 (in Japanese).

Kagan, Y., 3-D rotation of double-couple earthquake sources, Geophys. J. Int., 106, 709-716, 1991.

Okada, Y., K. Kasahara, S. Hori, K. Obara, S. Sekiguchi, H. Fujiwara, and A. Yamamoto, Recent progress of seismic observation networks in Japan-Hi-net, F-net, K-NET and KiK-net-, Earth Planets Space, 56, xv-xxviii, 2004.

United States Geological Survey, USGS Centroid Moment Solution NEAR EAST COAST OF HONSHU, JAPAN, http://earthquake.usgs.gov/earthquakes/eqinthenews/2011/ usc0001xgp/neic_c0001xgp_cmt.php, 2011.

Wessel, P. and W. H. F. Smith, New version of the Generic Mapping Tools released, Eos Trans. AGU, 76, 329, 1995.

Y. Asano (e-mail: asano@bosai.go.jp), T. Saito, Y. Ito, K. Shiomi, H. Hirose, T. Matsumoto, S. Aoi, S. Hori, and S. Sekiguchi 